\title{
Attributions and Appraisals of Workplace Incivility: Finding Light on the Dark Side?
}

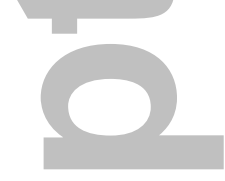

1

\section{Abstract}

Ample research demonstrates that workplace incivility has individual and organizational costs, but an important question remains unanswered: might it have benefits as well? We investigate this possibility by focusing on incivility appraisals - both negative and challenge (i.e., as an opportunity for learning, growth) - and their correlates. To explain this diversity of appraisals, we examine whether attributions (i.e., perceived intent to harm, perceived perpetrator control) predict perceptions. We conducted two multi-method (quantitative and qualitative) surveys, one of which was multi-source, of employees across a range of occupations. In Study 1, attributions that perpetrators acted with control and malicious intent fueled negative appraisals of incivility, which undermined job satisfaction. Study 2 added to these findings by demonstrating that some targets formed challenge appraisals of uncivil encounters, especially when they attributed low malicious intent to perpetrators; challenge appraisal related to boosts in job satisfaction and thriving. These attitudinal outcomes then positively related to organizational citizenship behavior, as reported by targets' coworkers. Showing paths to incivility harm (and potential benefit), our findings can inform interventions to alter the impact of workplace incivility.

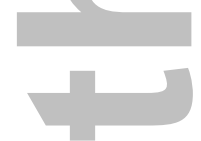

Keywords: incivility; cognitive appraisal; attribution; job satisfaction; thriving at work; organizational citizenship behavior; United States

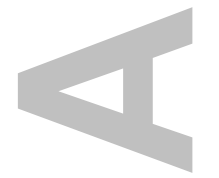

This is the author manuscript accepted for publication and has undergone full peer review but has not been through the copyediting, typesetting, pagination and proofreading process, which may lead to differences between this version and the Version of record. Please cite this article as doi:10.1111/ apps.12127. 


\section{Attributions and Appraisals of Workplace Incivility: Finding Light on the Dark Side?}

Workplace incivility has grabbed the attention of scholars within the last several decades. The psychology and organizational behavior literatures are replete with studies demonstrating the pervasiveness of incivility (i.e., $60 \%$ or more of employees across industries; Cortina $\&$ Magley, 2009; Cortina, Magley, Williams, \& Langhout, 2001; Pearson \& Porath, 2005), as well as its implications for employee well-being, including lower job satisfaction and performance, and greater job withdrawal, psychological distress, and turnover intentions (e.g., Cortina et al., 2001; Lim, Cortina, \& Magley, 2008; Porath \& Erez, 2007). Yet only a handful of scholars have attempted to unearth the pathways through which incivility influences employees.

Though similar to other forms of antisocial work behavior (e.g., aggression, bullying), workplace incivility is a low-level form of deviance in which workplace norms for respect are violated (Andersson \& Pearson, 1999). By definition, incivility is both subtle and ambiguous (Andersson \& Pearson, 1999), which may lead targeted employees to engage in greater cognitive efforts to "make meaning" of these rude encounters, compared to more overt forms of mistreatment that contain clearer intentions. Preliminary research has highlighted subjective perception as an important aspect of incivility (e.g., Cortina \& Magley, 2009). We extend this literature by asking provocative new questions: Is incivility ever perceived in a positive light? Can it be generative, yielding developmental moments of learning and growth? Applying conservation of resources theory (Hobfoll, 1989) and tenets of positive psychology, we propose that appraisals of workplace incivility sometimes extend beyond the negative and incorporate positive notions of "challenge." Some stressors assumed to be negative can be (and often are) assessed as learning and growth opportunities (Hobfoll, 1989; Schaefer \& Moos, 1998), a notion we apply to the incivility literature. In addition, we propose that targets' attributions for why the 
incivility occurred are central to their appraisals (both negative and challenge), which can then shape their outcomes (both harms and benefits).

The novel contributions of this project are threefold, in that we (a) determine whether and under what circumstances targets form challenge appraisals of uncivil events, (b) identify factors that fuel these multifaceted incivility appraisals, and (c) investigate how appraisals relate to variations - including boosts - in target well-being and performance. Our paper questions the assumption that incivility is "all bad all the time" by incorporating principles of positive psychology, thereby shifting consensus about incivility (Hollenbeck, 2008). To achieve these goals, we blend quantitative and qualitative methods and collect data from multiple sources. Figure 1 summarizes our hypothesized model.

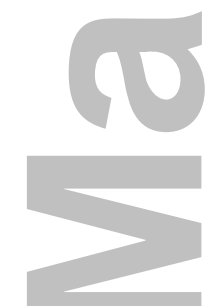

Insert Figure 1 about here

\section{Appraisals of Workplace Incivility}

Research on workplace incivility has demonstrated that targets form mildly negative appraisals (Cortina \& Magley, 2009). Building on this foundation, we ask whether uncivil treatment always results in negative appraisals. Stressors are often not clearly positive or negative, and as such, are subject to personal appraisal (Hobfoll, 1989). Appraisal is a universal meaning-making process through which people evaluate the nature of events and their implications for well-being (Lazarus \& Folkman, 1984; Spell \& Arnold, 2007). Multiple types of appraisal exist, including harmful (having caused harm), threatening (suggesting future harm), and challenging (posing growth or learning opportunities; Lazarus \& Folkman, 1984). Despite its seeming unlikelihood, individuals form positive, challenging appraisals of stressful experiences 
with surprising frequency, as exemplified in research on partners of terminal AIDS patients (Moskowitz, Folkman, \& Acree, 2003; Stein, Folkman, Trabasso, \& Richards, 1997), targets of student bullying (Matsunaga, 2011), and victims of war, divorce, and physical illness (Schaefer \& Moos, 1998). Because incivility is both subtle and ambiguous (Andersson \& Pearson, 1999), we propose that appraisals (and subsequent outcomes) of it may vary too. Specifically, while incivility often elicits negative appraisals, it may also be experienced as a growth opportunity.

Targets may form challenge appraisals of incivility for several reasons. According to conservation of resources theory (Hobfoll, 1989), people strive to accumulate and protect their resources (e.g., social, psychological, physical). Rather than viewing incivility solely as a threat to one's resources, targets may view it as a challenge through which resources can be gained, either by learning from one's mistakes or by performing at a higher level. Related, targets may draw on uncivil experiences to guide their future behavior, thereby using these incidents as resources to navigate - and improve their outcomes in - similar situations (Pillemer, 2003). Challenge appraisals might also be part of a larger coping mechanism, providing a psychological reprieve by preventing negative thoughts, infusing positive meaning into experiences, buffering physiological stress reactions, and ultimately replenishing resources (Folkman \& Moskowitz, 2000a). Thus, challenge appraisals of incivility are likely to bolster and protect various facets of targets’ resources.

\section{What Fuels Incivility Appraisals? Causal Attributions}

Why might some individuals appraise incivility as a negative event, while others perceive it as a growth opportunity? Scholars propose that causal attribution shapes appraisals (Lazarus \& Folkman, 1984). Based on attribution theory, people strive to answer, "Why did this event occur?" (Kelley \& Michela, 1980) due to ever-present desires to understand one's environment 
and experience control (Heider, 1958), particularly following unpleasant events (Bohner, Bless, Schwarz, \& Strack, 1988). We focus on two specific attributions - perceived perpetrator intent to harm and control - apt to be central to appraisals of incivility due to its ambiguous nature.

Perceived intent to harm may be one of the most significant factors influencing victims' experiences of workplace mistreatment (Herschovis, 2011). Perceived intent incites the strongest feelings of anger and hurt, compared to other attribution facets (Weiner, Amirkhan, Folkes, \& Verette, 1987). It damages relationships by creating interpersonal distance (Vangelisti \& Young, 2000) and decreasing forgiveness (Struthers, Eaton, Mendoza, Santelli, \& Shirvani, 2010).

Targets of abusive supervision are more likely to retaliate via counterproductive work behaviors (CWB) when they perceive greater malicious intent (Eschleman, Bowling, Michel, \& Burns, 2014). When an employee is targeted with rude treatment, such as not being given necessary information, perceived intent is key. If the lack of information is attributed to an intentional attempt to exclude or to hinder one's performance, the appraisal will be highly negative, according to both attribution and appraisal theories (Kelley \& Michela, 1980; Lazarus \& Folkman, 1984). However, this proposition regarding the relationship between attribution and appraisal has receive little empirical investigation. Thus, we hypothesize:

Hypothesis 1: The more targets attribute an uncivil event to perpetrator intent to harm, the stronger their negative appraisals of the uncivil event.

What happens to appraisal of incivility when targets do not perceive intent to harm?

Rather than dismissing unintentional incivility, targets will still deem it important to make sense of the situation and assess its underlying meaning, because individuals feel entitled to accounts of events - particularly negative events - that could affect their well-being (Bohner et al., 1988; Miller, 2001). This entitlement may explain targets' greater meticulousness when evaluating 
unintentional, compared to intentional, rude behavior (Vangelisti \& Young, 2000). Assessments of unintentional rude acts are more likely to generate challenge appraisals and consideration of potential benefits (Vangelisti \& Young, 2000). Infusing rude but unintentional events with positive meaning - such as the opportunity to learn - may be adaptational (Lazarus, 2000), allowing targets to gain a sense of personal control, mastery, or even self-esteem (Folkman \& Moskowitz, 2000a; Schaefer \& Moos, 1992).

These explanations illuminate why negative events deemed unintentional can elicit empathy (Betancourt \& Blair, 1992) and helping behavior (Martinko, Harvey, \& Douglas, 2007). They may "soften" evaluations (p. 396, Vangelisti \& Young, 2000) and even foster closer relationships (Clark \& Grote, 1998). Unintentional negative acts can be assessed as prosocial, supportive, strategic, and justified, which appear to increase relational satisfaction (Vangelisti \& Young, 2000). Drawing on this work, we propose that unintentional attributions can potentially benefit targets by fostering challenge appraisals. For example, a supervisor may harshly demand more from team members; if targets do not perceive the situation as intending harm, they are more likely to infer that the behavior is well-intentioned (e.g., aiming to improve performance), thereby viewing the encounter as an opportunity to push themselves and grow.

Related, Eschleman and colleagues (2014) coined the term motivational intent to capture subordinates' beliefs that abusive supervision is intended to promote higher job performance, rather than to harm subordinates. Interestingly, Eschleman and colleagues (2014) found that motivational intent did not decrease subordinates' engagement in CWB following abusive supervision, meaning that it did not buffer against a negative response, as hypothesized. Our study differs from, and builds on, this work in several important ways. First, rather than testing attribution as a moderator of the relationship between mistreatment frequency and target 
outcomes, we model it as an antecedent to appraisal of mistreatment. In doing so, our goal is to provide an empirical test of the proposition that attribution influences appraisal of an event, which is then a proximal predictor of one's outcomes (Lazarus \& Folkman, 1984). In addition, theories of attribution and appraisal posit that these facets of meaning-making pertain to specific events (and vary between events), leading to our adoption of the critical incident technique (see Methods). This differs from attributional style, a stable characteristic that captures one's tendency to adopt similar attributions across situations (Brees, Mackey, \& Martinko, 2013). Eschleman and colleagues' (2014) findings suggest that motivational intent, measured similarly to attributional style, does not influence targets' reactions to abusive supervision in the aggregate (i.e., when assessing a history of abuse from one's supervisor). However, prosocial attribution may affect targets' reactions to individual mistreatment incidents, consistent with attribution theory (Kelley \& Michela, 1980). That is, it is seemingly difficult for employees to broadly attribute good intentions to a collection of mistreatment experiences, but they may form these attributions when evaluating discrete events. Taken together, we attend to "positive" meaningmaking of specific incidents of incivility, specifically modeling unintentional attribution - which encompasses prosocial motives (Vangelisti \& Young, 2000) - as an antecedent to challenge appraisal:

Hypothesis 2: The less targets attribute an uncivil event to perpetrator intent to harm, the stronger their challenge appraisals of the uncivil event.

We evaluate a second type of attribution, perceived perpetrator control (i.e., whether the cause of the event resided within the perpetrator, rather than within another individual or being due to circumstantial forces), to further uncover the role of attribution in target meaning-making of incivility. Rather than modeling perceived perpetrator control as a direct predictor of 
appraisal, perceived control has been proposed to predict our other attribution of interest, perceived intent to harm (Martinko \& Zellars, 1998). That is, perceived control, which includes assessments of perpetrator ability and knowledge of consequences (Jones \& Davis, 1965), seems to be a prerequisite for inferring intent (malicious or otherwise) of a perpetrator's uncivil actions. This proposition could explain why the belief that perpetrators possessed control over their actions causes targets of aggression to feel more upset (Keashly \& Neuman, 2008) and desire interpersonal distance following broken social contracts (Weiner et al., 1987). Perceived control seemingly accompanies perceived intent to harm, and we contend it is another key attribution underlying targets' reactions. We test scholars' propositions about the relationship between attributions of control and intent through the following hypothesis:

Hypothesis 3: The more targets attribute an uncivil event to being within perpetrator control, the stronger their attributions of perceived intent to harm.

\section{What Follows Incivility Appraisals?}

The importance of incivility appraisal rests in its relationship with target well-being. Based on the earlier discussion of conservation of resources theory (Hobfoll, 1989), assessing incivility negatively will increase targets' feelings of stress and deplete their resources, whether social, psychological, financial, or otherwise. Resource loss likely explains the well-documented relationship between negative appraisal and adverse attitudinal and occupational outcomes (Sinclair, Martin, \& Croll, 2002; Tomaka, Blascovich, Kelsey, \& Leitten, 1993). It may also explain preliminary research showing that negative assessments of incivility - including negative emotions - predict detrimental reactions and attitudes (e.g., Porath \& Pearson, 2012).

Conversely, appraising events as challenges through which resources can be gained buffers the stress response and improves psychological, physical, and social functioning 
(Hobfoll, 1989). Through challenge appraisals, individuals can learn to improve their performance, problem solve, address similar events in the future (Pillemer, 2003), as well as adopt more effective coping mechanisms (Folkman \& Moskowitz, 2000a, 2000b). Indeed, challenge appraisals have been shown to lead to a host of positive outcomes, including higher morale (Stein et al., 1997), creativity and proactive behavior (Ohly \& Fritz, 2010), and performance (Tomaka et al., 1993). Despite growing research on challenge appraisal of negative events, this appraisal has not yet been considered within incivility research. Is there light on this "dark side" of organizational life?

We examine relationships between incivility appraisals and two outcomes: job satisfaction and thriving at work. First, job satisfaction is one of the most commonly studied outcomes, specifically within mistreatment research (e.g., Lim et al., 2008; Hershcovis, 2011). Although ample research has demonstrated a link between mistreatment frequency and job satisfaction, we expand on this work by proposing that target appraisal (negative and challenge) is a theoretically meaningful driver of this popular outcome. Loss of resources following negative appraisal should lower job satisfaction, while resource gains following challenge appraisal should heighten it (Hobfoll, 1989).

We also test the relationship of appraisal with a construct stemming from positive psychology: thriving at work. Thriving is a subjective state related to one's ability to adapt to environmental changes and develop over time (Spreitzer, Sutcliffe, Dutton, Sonenshein, \& Grant, 2005). It captures employees' abilities to both learn and experience vitality - increasingly important capabilities in organizations (Porath, Spreitzer, Gibson, \& Garnett, 2012). The learning facet describes one's sense of improvement at work, such as mastering skills or knowledge that can increase performance. The vitality facet taps into one's energy, stamina, and intensity at 
work. Both facets are central to thriving, differentiating it from related concepts (e.g., flow, flourishing; Spreitzer et al., 2005). Thriving is particularly pertinent to the study of incivility appraisal for several reasons. First, the socially embedded model of thriving emphasizes the relational nature of thriving, positing that social interactions at work are central to shaping both vitality and learning (Spreitzer et al., 2005). As one of the most prevalent forms of workplace mistreatment (Pearson \& Porath, 2005), incivility is apt to be an important social interaction that influences employee thriving. Second, appraisal is likely to be a proximal predictor of thriving, because according to the socially embedded model of thriving, employees experience greater vitality and learning when resources are gained (e.g., via challenge appraisal; Spreitzer et al., 2005). The opposite should occur for resource loss following negative appraisal. Put differently, appraising incivility as challenging will foster energy and development (vice versa for negative appraisal).

In line with I/O scholars' calls to combine levels of analysis in well-being research (Ilies, Aw, \& Pluut, 2015), we test the relationships between employees' appraisals of specific uncivil experiences and their global job satisfaction and thriving at work. Demonstrating the impact of episodic events on broader outcomes is theoretically important, because it enhances knowledge of the psychological processes that influence well-being, thereby helping uncover its etiology (Mazzeo, Bergman, Buchanan, Drasgow, \& Fitzgerald, 2001). Practically speaking, we provide a conservative test of the effects of specific uncivil incidents on important outcomes. Withinindividual variables explain a third of the variance in job satisfaction (Ilies et al., 2015), underscoring the significant effect that individual events have on employee well-being.

Ample empirical evidence also supports the value of combining levels of analysis (Adler, Lodi-Smith, Philippe, \& Houle, 2016). Meaning-making of specific events (e.g., appraisal of 
sexual harassment, assessments of romantic encounters) has repeatedly been shown to predict individuals' global attitudes and well-being, including job satisfaction, relational satisfaction, and psychological adjustment (Alea \& Vick, 2010; Langhout et al., 2005; Philippe, Koestner, Lecours, Beaulieu-Pelletier, \& Bois, 2011). The memory of an experience clearly shapes global facets of one's life, particularly in domains related to the experience (e.g., a work experience shaping work-related outcomes; Pillemer, 2003).

The memory of an event affects global well-being through numerous mechanisms, which scholars have broadly classified as self (i.e., constructing a sense of identity, unity, purpose), social (i.e., building interpersonal relationships, garnering empathy and support), and directive (i.e., problem solving and guiding future attitudes and behaviors; Adler et al., 2016). Memories, especially of disruptive events, are often activated without conscious awareness in order to guide behavior in similar future situations; this reactivation creates memory networks that affect general well-being (Philippe, Koestner, Beaulieu-Pelletier, Lecours, \& Lekes, 2012). In this way, specific memories have an active force on outcomes (Philippe et al., 2012), not only in the shortterm but importantly, over time (Adler et al., 2016). Applied to the current study, we propose that appraisals of discrete uncivil events relate to overall job satisfaction and thriving at work:

Hypothesis 4: The more strongly targets appraise an uncivil event as negative, the lower their (a) job satisfaction, (b) learning-related thriving at work, and (c) vitality-related thriving at work.

Hypothesis 5: The more strongly targets appraise an uncivil event as challenging, the higher their (a) job satisfaction, (b) learning-related thriving at work, and (c) vitalityrelated thriving at work.

\section{Links to Organizational Citizenship Behavior}


Appraisal is a private mental process, not readily available to others (Lazarus \& Folkman, 1984). As hypothesized earlier, appraisal proximally relates to unobservable facets of targets' psychological states (i.e., job satisfaction, thriving). We extend this analysis by examining whether these unobservable attitudes, in turn, relate to observable outcomes (i.e., behavior). According to the MODE model (Fazio, 1990), individuals' attitudes manifest in observable behavior in a number of ways, both deliberately and spontaneously. Consistent with this model, organizational research has demonstrated that a host of job attitudes predicts work behavior, such as turnover (Podsakoff, LePine, \& LePine, 2007), organizational citizenship behavior (OCB: voluntary tasks that exceed job requirements; Organ \& Ryan, 1995; Podsakoff, MacKenzie, Paine, \& Bachrach, 2000), and other facets of performance (Judge, Thoresen, Bono, \& Patton, 2001; Riketta, 2008). Drawing on the MODE model and this empirical work, we propose that job attitudes mediate relationships between targets' incivility appraisals and their observable behavior (as reported by coworkers).

$\mathrm{OCB}$, a component of job performance, is a particularly valuable contributor to organizational effectiveness. Employees are less likely to engage in OCB following workplace rudeness (Porath \& Erez, 2007), and we investigate whether appraisals and their corresponding attitudes help explain this relationship. Job satisfaction is particularly likely to influence OCB, given research that dissatisfied employees are less apt to "give back" to their organizations (Organ \& Ryan, 1995). Despite the well-established relationship between job satisfaction and OCB, scholars have called for continued research on the topic, frowning upon declining attention to it (Judge et al., 2001). We answer this call by testing whether incivility targets' job satisfaction relates to coworkers' reports of their OCB. 
Further, we assess whether thriving at work (both learning and vitality facets) explains variance in targets' OCB. Scholars have proposed that thriving enhances mental and physical health (Spreitzer et al., 2005), and preliminary empirical work supports its relationships with greater career development initiative and lower burnout (Porath et al., 2012). When employees feel more energized (i.e., vitality) and motivated to engage in developmental opportunities (i.e., learning), their performance is apt to improve (Porath et al., 2012). Consistent with conservation of resources theory (Hobfoll, 1989), thriving employees are more likely to possess resources needed to bolster to their own and their organizations' success (Spreitzer et al., 2005). Given this, we propose that thriving relates to employees' willingness to contribute to their organizations through OCB. Through these pathways, the effects of incivility may spread throughout organizations.

Hypothesis 6: (a) Job satisfaction, (b) learning-related thriving at work, and (c) vitalityrelated thriving at work mediate the relationship between negative appraisal and OCB. Hypothesis 7: (a) Job satisfaction, (b) learning-related thriving at work, and (c) vitalityrelated thriving at work mediate the relationship between challenge appraisal and OCB.

\section{Project Overview}

Study 1 addresses predictors of negative appraisal of incivility, namely attributions of perpetrator intent to harm and control. We also test whether negative appraisal of incivility relates to job satisfaction. We study these relationships quantitatively and then use qualitative data to (a) probe the breadth of incivility appraisals (e.g., do participants ever describe challenge appraisals?), (b) validate the negative appraisal measure, and (c) learn more about the nature of incivility attributions (e.g., do targets' narratives reflect perceived control as a prerequisite for perceived intent? How can perceived intent be measured more thoroughly?). We extend the 
model in Study 2 by including challenge appraisal of incivility, focusing in greater detail on intentional attribution, and testing implications for workplace thriving. We use qualitative data to validate the concept of challenge appraisal, as well as the importance of perceived intent to harm in shaping appraisals. Finally, we test whether incivility appraisals relate to observable citizenship behavior (coworker-reported) via targets' private attitudes (i.e., job satisfaction, thriving).

\section{Study 1}

\section{Method}

Study 1 was part of a larger investigation into women's work experiences in a Midwestern metropolitan area. We advertised an initial online "snapshot survey" through outreach to 50 organizations, social media sites, flyers, and a press release. A total of 4,776 women completed the initial survey and 3,593 (75\%) enrolled to take a longer paper-based survey. We randomly selected 500 respondents, to whom we mailed paper surveys. We adhered to Dillman and colleagues' (2008) survey design recommendations, including reminder postcards, replacement surveys, and $\$ 2$ bill incentives. The response rate was $85 \%$; we excluded five surveys due to invalid completion, resulting in $n=419$.

Participants in the final dataset were $M=42.24$ years old $(S D=10.34)$. Many held bachelor's degrees (39\%) and graduate/professional degrees (50\%). Races/ethnicities were: White (54\%), African American (19\%), Asian American/Pacific Islander (16\%), and Latina $(6 \%)$. Subjects worked in diverse occupations (e.g., biomedical research, retail, transportation), and $91 \%$ worked full-time. Average organizational tenure was 9.2 years $(S D=8.2)$. 


\section{Procedure and Measurement}

Most recent uncivil experience. Respondents completed the Workplace Incivility Scale (WIS; Cortina et al., 2001) and a cyber-incivility scale (Lim \& Teo, 2009). If respondents endorsed at least one incivility item, they were asked to describe their "most RECENT incivility incident." We probed participants about a recent experience in order to: (1) gather detailed information about a particular uncivil incident, because appraisal and attribution are specific to individual experiences (Lazarus \& Folkman, 1984), and (2) prime participants with a focal experience to make memories salient from the uncivil encounter.

Negative appraisal. We adopted a negative appraisal measure of incivility (e.g., “offensive") by Cortina and Magley (2009). After extensively reviewing theoretical and empirical work on appraisal (e.g., Lazarus \& Folkman, 1984), we broadened this measure to assess the construct domain as fully as possible, adding three items: "hurtful", "serious", and "stressful". Participants responded to each item following the stem, "How would you describe this recent [uncivil] experience?" from 1 (not at all) to 5 (extremely).

We examined the expanded measure's psychometric properties, including internal consistency reliability, factor structure, and discriminant validity. The ten items showed high reliability $(\alpha=.92)$ and, based on principal axis factoring (PAF), contained a unidimensional structure. The measure demonstrated discriminant validity, as it contained a trivial (nonsignificant) relationship with trait pessimism in a CFA $(\Phi=.07)$, indicating that negative appraisals do not simply reflect respondents' cynical tendencies.

Attributions: Perceived perpetrator control and intent to harm. Consistent with The Attributional Style Questionnaire (Peterson et al., 1982) method for preventing alteration of attributions during Likert-scale item responding (Kent \& Martinko, 1995), participants first 
described what they believed was the one major cause of their recent incivility incident. We then assessed perceptions of perpetrator control via two Likert-scale items $(r=.64)$ from the Occupational Attributional Style Questionnaire (Furnham, Sadka, \& Brewin, 1992; e.g., "Was the cause controllable by the primary person involved?). To assess perpetrator intent, we drew the pertinent item (“Did the primary person commit the behavior on purpose?") from The Causal Dimension Scale (Russell, 1982). Participants responded to these items on 5-point scales, with anchors tailored to the items (e.g., not at all on purpose to completely on purpose).

We assessed the convergent and discriminant validity of both attribution measures. In a CFA, perceived control and intent significantly correlated with one another $(\Phi=.39)$ but did not relate to trait pessimism ( $\Phi=-.03$ with control; $\Phi=.08$ with intent). In other words, these measures do not simply reflect negative worldviews.

Job satisfaction. We measured job satisfaction, from 1 (strongly disagree) to 7 (strongly agree), using Cammann, Fichman, Jenkins, and Klesh’s (1983) Michigan Organizational Assessment Questionnaire (e.g., "All in all, I am satisfied with my job”; three items, $\alpha=.87$ ).

Control variables. A pessimistic outlook on life may affect target meaning-making of uncivil encounters, potentially amplifying negative responses (Judge \& Hulin, 1993). We therefore controlled for respondent pessimism - a common operationalization of negative disposition - to ensure that reports of greater incivility, perceived intent and control, and negative appraisal were not simply functions of cynical worldviews. We used six items (e.g., "If something can go wrong for me, it will”) from the Life Orientation Test (Scheier, Carver, \& Bridges, 1994; $\alpha=.83$ ), rated from 1 (strongly disagree) to 5 (strongly agree).

In addition, research demonstrates that targets' past mistreatment experiences influence their appraisals of subsequent mistreatment (e.g., Bergman, Langhout, Palmieri, Cortina, \& 
Fitzgerald, 2002; Cortina \& Magley, 2009). Repeated exposure to mistreatment can amplify negative appraisals of events that follow. To account for this effect, we controlled for respondents' perceived exposure to incivility over the past year (from 1: never to 5: very often), using the WIS and cyber-incivility scales $(\alpha=.88)$.

\section{Protections against Common Method Bias}

Given the personal nature of the constructs (e.g., private attributions and appraisals), selfreport measurement was essential (Chan, 2009; Podsakoff, MacKenzie, \& Podsakoff, 2012). According to Lazarus and Folkman (1984), self-report is the most appropriate method for addressing appraisal, ultimately producing more measurement benefit than harm. While this may raise questions about common method bias, we built features into the study designs to minimize such bias ex ante, following recommended procedures (Podsakoff et al., 2012). First, surveys were anonymous, reducing social desirability and response consistency pressures and promoting honest responding. Second, criterion variables appeared prior to and independent from predictor variables; their separation decreased the salience of participants' initial responses during later responses. Third, scale formats (e.g., scale type, anchor labels) varied across variables to reduce anchor- and end-point-bias. Study 2 included coworker reports of target behavior, testing relationships uncontaminated by single-source bias. In addition to procedural remedies, we statistically addressed common method bias ex post by modeling pessimism and incivility history as latent constructs and partialing out their effects.

\section{Results}

Descriptive statistics and correlations appear in Table 1. Of all respondents, $88.3 \%$ experienced at least one incivility incident within the last year. A fifth of respondents described 
an uncivil incident that occurred in the past week; $29.2 \%$ occurred in the last 30 days, $37.2 \%$ occurred in the last one to six months, and $13.5 \%$ occurred six or more months ago ${ }^{1}$.

Insert Table 1 about here

\section{Structural Equation Model}

Using LISREL, we tested the relationships in Figure 2. We first estimated a measurement model to ensure that psychometric properties and factor loadings were appropriate. We then estimated a structural model, evaluating fit using "incremental" and "absolute" fit indices (Hu \& Bentler, 1999). Items were randomly allocated across three indicators per latent construct, except control (two indicators) and intent (one indicator). One loading per indicator was fixed to one.

Goodness of fit statistics for the measurement model revealed good fit: Minimum Fit Function $\chi^{2}(76, N=331)=119.78, p<.01, \mathrm{RMSEA}=.042,90 \%$ CI $[.027, .056], \mathrm{CFI}=.98$, and $\mathrm{NNFI}=.98$. All completely standardized factor loadings were significant, ranging from .57 to 93. We then tested the structural model, which fit the data well: $\chi^{2}(83, N=331)=175.13, p<$ $.01, \mathrm{RMSEA}=.058,90 \% \mathrm{CI}[.046, .070], \mathrm{CFI}=.97, \mathrm{NNFI}=.96$. All hypothesized paths were significant, even controlling for pessimism and incivility history (see Figure 2).

Hypothesis 1 was supported: the more intent to harm targets believed perpetrators held, the more negatively they appraised uncivil experiences (35.3\% of variance explained). Greater perceived controllability positively related to perceived intent to harm (18.4\% of variance explained), supporting Hypothesis 3. In line with Hypothesis 4a, the more negatively targets appraised incivility, the lower their job satisfaction ( $4.1 \%$ of variance explained).

\footnotetext{
${ }^{1}$ We reran the models in both studies adding time since the uncivil event as a covariate, and the results remained unchanged.
} 
We compared this model to a larger alternative, adding a path from perceived intent to job satisfaction to test whether appraisal partially or fully mediated this relationship. This model did not lead to a significant improvement in fit $\left(\Delta d f=1, \Delta \chi^{2}=0.19, p>.975\right)$, and perceived intent did not relate to job satisfaction $(\beta=-.03)$. Therefore, negative appraisal fully mediated the relationship between perceived intent and job satisfaction. We tested a second alternative model that contained a path from perceived control to negative appraisal. Perceived control did not significantly relate to negative appraisal $(\beta=.15, \mathrm{t}=1.89)$, and this model had only a slight improvement in fit over the original model $(\Delta \mathrm{df}=1, \Delta \chi 2=4.00, \mathrm{p}=.046)$. Therefore, perceived intent fully mediated the relationship between perceived control and negative appraisal.

\section{Qualitative Analysis: Elaborating on Constructs and their Measurement}

Following Edmonson and McManus' (2007) framework for methodological fit and blending qualitative and quantitative data, we examined respondents' descriptions of their uncivil experiences in order to (1) evaluate the breadth of appraisals of and attributions for incivility, and (2) assess the validity of the negative appraisal measure. We followed Braun and Clarke's (2006) guidelines for thematic analysis, which "is a method for identifying, analyzing, and reporting patterns (themes) within data" (p. 79). Unlike content analysis, thematic analysis does not center on frequency counts of words or phrases; rather, it allows researchers to identify meaningful themes across multiple data points (Braun \& Clarke, 2006). Specifically, we adopted a theoretical (deductive) approach, such that we used our research questions and theory to guide the coding procedure. Themes were identified and noted when respondents' incivility narratives 
reflected appraisals (defined as the underlying meaning of the event for oneself, such as harmful), attributions (defined as the perceived cause of the event), or relationships between study variables (e.g., between appraisal and outcomes). We identified themes when they were semantic (explicit and "surface level"), as well as when they were latent, meaning they captured fundamental meanings and concepts underlying targets' descriptions. A key determinant of themes was their importance in addressing the focal research questions (Braun \& Clarke, 2006). Braun and Clarke (2006) outline six phases of thematic analysis, including generating initial codes and searching for and reviewing themes. These phases should not necessarily be followed strictly and sequentially as in quantitative analyses but rather, should be used iteratively and applied flexibly based on one's research questions and data. Thus, in the current study, we focused most heavily on searching for and reviewing themes that were rooted in the study's underlying theoretical frameworks for appraisal and attribution.

Thematic analysis revealed three main themes of incivility appraisals: neutral (neither positive nor negative), challenge (potential for learning, growth, problem solving, or any other positive assessment), and negative (harmful and/or threatening). In the neutral appraisal theme, targets noted an absence of negative (and positive) appraisal, making statements such as "I don't take offense," "No big deal,” and “...[It] is easily resolved, especially if you don’t take it too seriously." In the challenge appraisal theme, targets evaluated incivility as an opportunity to learn and develop. Some stories mapped onto language from the positive psychology and posttraumatic growth literature precisely (i.e., semantic level), describing uncivil experiences as "a learning curve" and as a way to "learn...to both accept and work around." These participants found the incidents helpful in teaching them how to respond to stressful work situations. As one respondent stated, "It gave me insight and now I know what to do in future situations." 
Challenge theme quotes such as these captured the directive function of memories, such that employees were using their past uncivil event as a problem solving guide during related, future encounters at work. Other challenge theme descriptions encompassed persistence in achieving goals or having needs met at work. Targets' narratives made clear that a broad range of incivility appraisals exist, which include learning and growth.

Beyond exemplifying challenge appraisals, respondents' descriptions provided an opportunity to validate the revised negative appraisal measure via the negative appraisal theme. Many targets assessed their experiences as "hurtful" ("I was truly hurt and upset"), citing rude jokes, social exclusion, and demeaning responses to suggestions. Targets also varied in how "serious" they found uncivil incidents, with perceived implications ranging from minor to significant (e.g., an unreturned email causing an inability to meet a critical deadline). In addition, many respondents described uncivil encounters as stress-inducing. Given qualitative support for the three new appraisal items, we retained them in Study 2. Conversely, we saw no evidence of incivility being appraised as "threatening" or "disturbing." Not only were these appraisal terms (and related language) not used in targets' narratives, they also received the lowest quantitative endorsements. These results informed our decision to remove these items from the negative appraisal measure in Study 2.

Next, we turned to participants' descriptions about why they believed perpetrators behaved uncivilly (i.e., attributions), finding significant variance. Perceived control and intent to harm were common themes: "The individual was exerting control over something in her life that she felt she could control" and "I believe she was trying to pull a power play over me." However, themes of low perceived control and intent clearly emerged as well, with targets frequently denying perpetrator wrongdoing: "Boss is overloaded with email and just overlooked it," "He 
was under work pressure," and "Miscommunication." While the quantitative results highlight the effects of malevolent attributions, these data extend those findings - and shift assumptions - by demonstrating that targets often believed their perpetrators could not control their actions and did not intend to mistreat them. These attributions often accompanied the challenge appraisal theme.

The attribution themes also supported our hypothesis that perceived control is a precursor to inferring intent to harm. When perceived intent could be inferred from a description (i.e., the perpetrator seemed to have a motive or goal), perceived control was high as well (i.e., the cause of the incident resided within the perpetrator, rather than being due to environmental or circumstantial forces or the target). For instance, one of the most common narratives was that perpetrators behaved uncivilly in order to attain or protect their power and authority (e.g., "Person [was] not happy with my advice/opinion; tried to pull a power card..." and "Someone wanting more authority, out of line, in office hierarchy"). Because there was an intentional goal or motive underlying the rude behavior (attaining power, authority), the perpetrator wielded control over the event. A related narrative that exemplified the high correlation between perceived intent and control described perpetrators acting rudely because they felt threatened, jealous, or insecure: "I feel she is very unsure of herself and insecure so she treats others badly to cover up her feelings." Perceived control as a prerequisite for perceived intent was also apparent when participants described incivility as being due to forces outside the perpetrator's control, such as work overload or miscommunication, which ultimately mitigated malicious intent. Given this additional support for Hypothesis 3 (supplementing the quantitative findings), we focused on perceived intent as a key driver of appraisal - and expanded its measurement - in Study 2.

\section{Study 2}

\section{Method}


U.S. employees were recruited through StudyResponse, an academic service. Online samples are more diverse than traditional samples (Gosling, Vazire, Srivastava, \& John, 2004), which was important for attaining adequate construct variance. StudyResponse invited 1,109 employees to participate and 886 began the survey (79.9\%). We screened the data, accepting surveys in which subjects responded to at least $90 \%$ of questions and correctly answered at least two of three effort response questions (e.g., "select disagree for this item"; Huang, Liu, \& Bowling, 2015). We deleted surveys with similar responses from identical IP addresses. These procedures yielded $n=479$. Average age was 42 years $(\mathrm{SD}=11.4) ; 60 \%$ of respondents were female. Races/ethnicities were: White (82.5\%); Asian/Pacific Islander (8.8\%), Black/African American (5.6\%), and Latino/a (4.6\%). Education levels were: 47\% college degree, 29.4\% high school degree or some college, $23.1 \%$ graduate degree. Average organizational tenure was 9.8 years $(\mathrm{SD}=7.3)$. All participants worked 30 or more hours per week.

We followed up with respondents to ask them to invite a coworker to complete a survey; this yielded coworker data for 160 focal respondents (33.4\%). Coworkers were $50.6 \%$ female, had known the focal respondent $M=7.7$ years $(S D=6.7)$, and $42.5 \%$ shared the focal respondent's job status (36.9\% were higher status, $20.7 \%$ were lower status).

\section{Procedure and Measurement}

Study 2 contained identical measurement as Study 1 for the most recent uncivil event, job satisfaction, pessimism, and incivility history. We used an expanded measure of intent and added measures of challenge appraisal, thriving at work, and (coworker-rated) OCB.

Negative appraisal. Most of the Study 1 negative appraisal items were used. We removed "disturbing" and "threatening" due to their low quantitative and qualitative 
endorsement in Study 1. These terms may in fact be antithetical to the low-intensity nature of incivility. The remaining items had good reliability $(\alpha=.88)$ and a unidimensional structure.

Challenge appraisal. A validated measure of challenge appraisal did not exist, so we developed one by drawing on relevant literature (e.g., Folkman \& Moskowitz, 2000a, 2000b; Lazarus \& Folkman, 1984), incivility narratives from Study 1, and input from seven subject matter experts (SMEs). The SMEs met multiple times to discuss potential items, resulting in a five-item measure (e.g., "a learning experience", “an opportunity for you to develop”), rated from 1 (not at all) to 5 (extremely). The items had a unidimensional structure and high reliability $(\alpha=.88)$. The measure showed a small relationship with trait pessimism in a CFA $(\Phi=-.20)$, speaking to its discriminant validity.

Perceived perpetrator intent. Given the theoretical and empirical importance of perceived intent to harm in incivility evaluations, we developed a more detailed measure, drawing on terminology in the attribution literature (e.g., Vangelisti \& Young, 2000), qualitative data from Study 1, and input from the SMEs. Like Study 1, participants wrote what they believed to be the main cause of their recent uncivil incident and then responded to nine Likert-scale items, such as "The primary person intended to hurt me in some way" from 1 (disagree strongly) to 5 (agree strongly). The measure contained high reliability $(\alpha=.84)$ and held a small relationship with trait pessimism $(\Phi=.14)$, speaking to its discriminant validity.

Thriving at work. Workplace thriving contains both learning (i.e., improving at one's work) and vitality (i.e., feeling energized at work) facets (Porath et al., 2012). Five items load onto "Learning" (e.g., "I find myself learning often") and five load onto "Vitality" (e.g., "I have energy and spirit"). Following the stem "At work...”, respondents rated each item from 1 (strongly disagree) to 7 (strongly agree). Both factors had high reliability (Learning: $\alpha=.91$; 
Vitality: $\alpha=.94)$. Porath et al. (2012) provide support for the measure's reliability, validity, and structure.

Coworker-reported OCB. We measured OCB using Lee and Allen's (2002) instrument. Coworkers answered, "To what extent does [coworker initials piped in] typically exhibit these behaviors at work?" from 1 (never) to 5 (many times). Eight items assessed OCB directed at individuals (OCB-I), and eight assessed OCB toward the organization (OCB-O). Given the strong correlation between OCB-I and OCB-O $(r=.81)$, we combined them into an aggregate OCB measure, which showed high reliability $(\alpha=.95)$.

\section{Results}

Descriptive statistics appear in Table 2. Most respondents (74\%) reported at least one incivility incident. Over a quarter (26.4\%) of incidents occurred in the past week; $34.5 \%$ in the last month, $30.4 \%$ in the last one to six months, and $8.7 \%$ six or more months ago.

\section{Insert Table 2 about here}

\section{Structural Equation Model}

We tested the Study 2 model (see Figure 3) using the same procedures as in Study 1 . The measurement model's fit indices were good: Minimum Fit Function $\chi^{2}(161, N=350)=411.31$, $p<.01, \mathrm{RMSEA}=.070,90 \% \mathrm{CI}[.062, .078], \mathrm{CFI}=.97, \mathrm{NNFI}=.97$. All completely standardized factor loadings (.80-.96) were significant. In the structural model, error terms for negative and challenge appraisals were allowed to correlate, as were error terms for job satisfaction and thriving. Note that we estimated correlations among the residuals of some endogenous latent variables only in very specific instances: when there was strong reason to 
expect those particular endogenous variables to covary, but no theoretical rationale for a particular directional relationship (i.e., no theory for why one variable would antecede the other). This model acceptably fit the data: $\chi^{2}(170, N=350)=561.42, p<.01, \mathrm{RMSEA}=.080,90 \% \mathrm{CI}$ $[.073, .087], \mathrm{CFI}=.96, \mathrm{NNFI}=.95$. All hypothesized paths were statistically significant, even controlling for pessimism and incivility history.

Consistent with Hypotheses 1 and 2, when respondents believed perpetrators committed incivility intentionally, they appraised incivility more negatively and less as a challenge. Negative appraisals related to lower job satisfaction and lower learning-related and vitalityrelated thriving at work (supporting Hypotheses 4a-c). The opposite was true for challenge appraisals, which related to greater satisfaction and thriving (consistent with Hypotheses 5a-c). Negative and challenge appraisals accounted for substantial variance in these outcomes: $17 \%$ of job satisfaction, $12 \%$ of learning-related thriving, and $15 \%$ of vitality-related thriving.

We again compared our model to a larger alternative, adding direct paths from perceived intent to the three outcomes. This model yielded improved fit, suggesting that appraisal partially mediates the relationships between perceived intent and outcomes $\left(\Delta d f=3, \Delta \chi^{2}=9.74, p<\right.$ $.025)$. Perceived intent negatively related to job satisfaction $(\beta=-.17, p<.05)$ but did not significantly relate to thriving ( $\beta=-.03$ with vitality; $\beta=-.05$ with learning). In the alternative model, negative and challenge appraisals still significantly related to all three outcome variables in hypothesized directions, speaking to their importance.

Insert Figure 3 about here

\section{Coworker-Reported OCBs}


To determine whether incivility targets' appraisals relate to their observable behavior, we tested the indirect effects of appraisals on (coworker-reported) OCB via job satisfaction and thriving. Bootstrapped tests of these indirect effects were computed using the PROCESS macro and $95 \%$ confidence intervals. Job satisfaction [-.129, -.003] and vitality-related thriving [-.135, .010] mediated the relationship between negative appraisal and OCB, such that these target attitudes related to greater OCB (supporting Hypotheses 6a and 6c). Learning-related thriving did not mediate this relationship (-.104, .003; contrary to Hypothesis 6b). Similarly, job satisfaction $[.005, .092]$ and vitality-related thriving $[.008, .114]$ (but not learning-related thriving; -.002, .103) mediated the relationship between challenge appraisal and OCB (supporting Hypotheses $7 \mathrm{a}$ and $7 \mathrm{c}$ but not $7 \mathrm{~b}$ ).

\section{Qualitative Data: Elaborating on Constructs and Their Relationships}

As in Study 1, we followed methodological fit recommendations by Edmonson and McManus (2007), as well as Braun and Clarke's (2006) phases of thematic analysis. We analyzed respondents' narratives about their recent uncivil encounters to identify themes that capture their appraisals and attributions, as well as to provide additional support for the novel (and counterintuitive) notion of challenge appraisal.

The results reinforce the idea that multiple appraisal themes for incivility exist (i.e., negative, challenge, neutral). The neutral appraisal theme was reflected in quotes such as "It really didn't bother me" and "I don't take it personally." Further, a challenge appraisal theme emerged; quotes such as "[The uncivil incident] only made me more determined to solve the problem" and "I'll find a solution on my own to whatever problem I need to email her about" again exemplify the directive function of memories, such that employees used them as resources and models to address similar future incidents. 
Some respondents recognized the potential for variance in employees' appraisals: “A supervisor spoke to me in a manner that was joking but could be deemed as derogatory to another person. It did not offend me but it could offend someone else.” Thus, despite incivility being facially negative, targets' interpretations of it varied, as the appraisal themes demonstrated. These narratives further validated the appraisal measures; "threatening" and "disturbing" did not appear, again supporting their exclusion, whereas descriptions of stress, severity, and hurt were present. Other respondents' narratives reflected the challenge appraisal items, such as opportunities to develop.

The data also reinforced the Study 1 attribution theme of perceived intent to harm. Many participants endorsed high intent to harm: “... they intentionally ignore my emails...” and "They said it was oversight but I think it was a slight done on purpose.” Many respondents, however, saw no intent to harm in perpetrator conduct: "[Emails] are often ignored not to be rude but [people] are too busy and forget to respond," and "The lack of communication isn't necessarily intentional - it's simply the way they operate." Some targets even recognized the importance of perceived intent: "Written communication needs to be written more carefully so that intent is clearly communicated.” Intent, whether present or absent, clearly factored into appraisals of incivility, as a relationship existed between the attribution and appraisal themes (e.g., intentional attributions linked to negative appraisals). These data also provided validity for the measurement of perceived intent - a construct that has been relatively unexplored in field settings.

The narratives supported possible causality between appraisal and target outcomes, bolstering the notion that individual perceptions carry the impact of mistreatment (Miner-Rubino \& Cortina, 2007). For some participants, incivility negatively affected their performance: “Their lack of response to emails affects my task completions" and "[The person's behavior] damaged 
the account and work culture... I was not able to focus on the work." Many discussed effects on commitment and turnover: "Lack of respect and response caused me to leave my last position to transfer to the one I have now," "Needless to say, that job didn't last very long," and "I am now at a new and thriving company." Conversely, targets who appraised uncivil encounters as challenges mentioned more positive outcomes: “...it has worked out very well” and "I was able to prove that my way was the right way and trust was renewed in my work."

\section{Discussion}

Why does workplace incivility derail the well-being of targeted employees, and do positive outcomes ever result? To answer these questions, we drew on conservation of resources theory (Hobfoll, 1989) and proposed that incivility appraisals, both negative and challenging, are key. We also applied attribution theory to identify factors that fuel incivility appraisal. The present study makes three noteworthy contributions to the literature.

First, we build on work asserting that appraisal plays a central role in targets' meaningmaking of workplace incivility (Cortina \& Magley, 2009) by demonstrating that targets can and often do - appraise uncivil events as challenges (i.e., opportunities to develop, learn). Nearly $72 \%$ of targets endorsed at least one challenge appraisal item regarding their uncivil experiences. These findings bridge the "dark side" of organizational psychology with positive psychology, as well as conservation of resources theory (Hobfoll, 1989), by demonstrating that some targets assess incivility as an experience through which resources can be gained, not only lost. The workplace mistreatment literature has not considered the possibility of challenge appraisal and its benefits.

Stronger negative appraisal of incivility related to lower target job satisfaction and thriving (learning and vitality) at work, while challenge appraisal positively related to these 
facets of well-being. Thus, at times, incivility may foster moments of growth. The influence of challenge appraisal is underscored by the increase in explained variance in job satisfaction (from $4 \%$ in Study 1 to $17 \%$ in Study 2) when challenge appraisal was incorporated in the model.

These results also contribute to the nascent literature on workplace thriving by demonstrating that challenge appraisal may be an influential predictor of this construct. Although crosssectional quantitative data cannot confirm causality between appraisals and outcomes, qualitative descriptions of participants' recent incivility experiences supported the direction implied by conservation of resources theory (Hobfoll, 1989). Taken together, the current studies contribute to theoretical understanding of the mechanisms through which incivility not only undermines employees but contributes to their growth and learning.

Of note, challenge appraisal of incivility does not exclude the possibility of negative appraisal. All targets who reported challenge appraisals acknowledged concomitant negative appraisals, and these two appraisals correlated positively in the Study 2 structural model. To illustrate this idea, an employee could find a coworker's uncivil comment hurtful and offensive but also assess it as an opportunity to better support her argument and express her voice in the future. This finding provides empirical support for proposals that individuals can adopt multiple appraisals simultaneously (Lazarus \& Folkman, 1984). Future research could further explore the impact of multiple appraisals on employee outcomes by investigating whether the types and severity of well-being outcomes differ when both appraisals are high, compared to when only one or the other is high.

In the second study contribution, we found evidence that beliefs about why perpetrators behaved badly - rooted in attribution theory (Heider, 1958; Kelley \& Michela, 1980) - relate to targets' appraisals of incivility. As hypothesized, the more intent to harm employees believed 
their perpetrators harbored, the more negatively they appraised uncivil situations. In contrast, targets who assessed incivility as unintentional were more likely to generate challenge appraisals. This finding builds on the few studies demonstrating that negative but unintentional messages can be perceived as opportunities for growth and learning (e.g., Vangelisti \& Young, 2000). It also extends research on motivational intent (Eschleman et al., 2014) by demonstrating that targets can form constructive attributions for uncivil events, which eventually relate to positive outcomes; however, as described in the Introduction, motivational (or constructive) attributions may need to be assessed concerning particular instances of mistreatment, rather than in reference to a history of mistreatment. Constructive attributions may also be more common for low-intensity, ambiguous mistreatment, such as incivility, compared to more egregious mistreatment, such as abusive supervision or active aggression. Because overt forms of mistreatment contain clearer intent to harm, they provide less room for interpretation, likely minimizing constructive attributions. Future research should put these possibilities to an empirical test, determining what attributions arise and how they operate with different types of mistreatment.

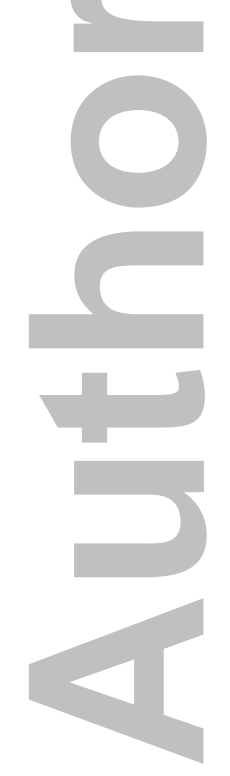


In the third study contribution, incivility appraisals related to observable citizenship behaviors indirectly via job satisfaction and vitality. That is, coworkers reported that certain targets - those who reported more positive appraisals and attitudes - engaged in more OCB. This demonstrates that unobservable appraisals can ultimately manifest in visible organizational behaviors via privately held attitudes, a finding that further contributes to theoretical understanding of the mechanisms through which incivility affects employees. More generally, by demonstrating that employees' self-reports converge with coworker reports, self-reported variables can be interpreted with greater confidence.

\section{Limitations and Future Directions}

Like all research, these studies have strengths and limitations. Common method bias is possible due to self-reported assessment of certain constructs. However, as discussed earlier, we used numerous procedural and statistical remedies (including other-reported data) to protect against common method effects. Even when common method bias exists, it does not typically invalidate significant relationships (Doty \& Glick, 1998), and it can cause underestimation (not only overestimation) of relationships (Chan, 2009; Podsakoff et al., 2012).

Participants in Study 1 were all women, which might raise questions about generalizability. We did not theorize gender differences in our model, because prior research has not found gender differences in relationships between incivility and other constructs (Lim et al., 2008). Indeed, Study 2 contained both women and men, and similar patterns were found as in Study 1. Further, in Study 2, women and men did not differ in their negative appraisal, challenge appraisal, or attributions of intent.

Measurement of the focal constructs (namely, appraisal and attribution) should be investigated and further validated in future studies. We adapted an existing measure of appraisal 
to capture targets' negative appraisals and had to develop survey-based measures of challenge appraisal and attribution, because none were available. Although we followed recommendations for measure development and provided initial evidence of validity, subsequent work could assess the psychometric properties of these measures in greater detail.

A fruitful future direction would be to examine trait-like individual differences that predict incivility targets' appraisals and attributions. For instance, workers with higher core selfevaluations may form optimistic appraisals and attributions as a self-preservation technique to minimize a victim identity, thereby upholding their high self-esteem and perceived control over situations (Brees et al., 2013). Given the role of personality in reported frequencies of incivility (Milam, Spitzmueller, \& Penney, 2009), agreeable targets might grant perpetrators the benefit of the doubt, assign low intent to harm, and form stronger challenge appraisals. Neurotic targets might do the opposite. However, a test of these propositions is warranted, given that target characteristics have not been found to predict appraisal of incivility (Cortina \& Magley, 2009); perhaps these characteristics more proximally affect attributions of incivility.

Further, a host of situational variables, including ascribed importance of work outcomes, organizational culture, leadership style, and work characteristics (e.g., time pressure), influence workers' attributions for events (Brees et al., 2013; Martinko, Gundlach, \& Douglas, 2002) and may play roles in our model. In particular, incivility targets may form stronger attributions of intent to harm (and subsequently more negative appraisals) when perpetrators wield greater power (Cortina \& Magley, 2009). Interestingly however, perpetrator status relative to the respondent did not relate to negative appraisal and attributions in Study 1, nor to negative and challenge appraisals and perceived intent in Study 2. Rather than negating the well-documented influence of perpetrator power on employee outcomes, we suggest it may moderate the 
relationship between attribution and appraisal (e.g., strengthening the link when instigators wield more power) or that status and power may have different effects given that they are not identical constructs (e.g., lower-status employees can hold substantial informal power). Taken together, future research could build on the current model by identifying key individual differences, as well as situational factors, that affect target meaning-making of incivility.

\section{Practical Implications}

By understanding the processes through which workplace incivility harms (and even benefits) employees, organizations can enact steps to prevent negative outcomes, rather than retrospectively addressing them. Foremost, organizations should strive to prevent incivility by critically evaluating norms, cultures, policies, and structures. When incivility occurs frequently and in varied forms, employees are more likely to adopt negative appraisals (and presumably, less likely to adopt challenge appraisals) of these events (Cortina \& Magley, 2009). By developing organizational cultures that minimize the occurrence of incivility, organizations can promote challenge and attenuate negative appraisal.

Differential effects on negative and challenge appraisals should also occur in organizations with cultures that foster healthy relationships between coworkers. Relationship quality appears to affect targets' assessments of disrespectful behavior (Miller, 2001), with highquality and close relationships fostering unintentional attributions (Vangelisti \& Young, 2000) that should, in turn, heighten challenge appraisals. Formal and informal sources of support also enhance the positive effects of stressors (Schaefer \& Moos, 1992), suggesting that uncivil conduct from otherwise supportive colleagues is more likely to be assessed as a challenge.

Drawing from impression management research, employees - particularly supervisors who often deliver negative feedback - should be educated about the power of communication 
(e.g., Schweiger \& DeNisi, 1991). Our respondents expressed this need: "We really need a communications course and conflict resolution in the workplace." During performance appraisals and developmental situations, a reprimand or below-average evaluation can be delivered in a rude manner, or interpreted that way by the subordinate if it is not communicated properly. What could otherwise be a developmental opportunity might be appraised negatively. Even if the message is not overtly rude but is simply unclear, the subordinate is likely to rely on subconscious and easy-to-process information, such as attributing the negative event to being within the supervisor's control (the fundamental attribution error; Jones \& Harris, 1967; Keashly \& Neuman, 2008), fueling negative appraisal. Communication skills training can teach employees to clarify their intentions for helping employees learn and grow. When feedback is clear and delivered respectfully, subordinates' use of inferences (e.g., perceived intent to harm) should decrease, ultimately reducing harm and increasing benefit. When employees do mistreat others, their apologizing and accepting responsibility can reduce targets' negative cognitions and retaliatory behavior (Martinko \& Zellars, 1998).

In industries where incivility runs high and is difficult to prevent (e.g., corrections), employees can be equipped with strategies for reframing negative experiences in a constructive manner, consistent with cognitive behavioral therapy (CBT; Beck, 1975). Through training rooted in CBT, employees can learn cognitive strategies that protect self-esteem, even in the face of frequent insult. By re-conceptualizing events constructively, one can avoid rumination and detrimental outcomes such as depression and burnout (Abramson, Seligman, \& Teasdale, 1978). In particular, CBT-related training has been effectively applied to alleviating negative outcomes associated with workplace stressors (de Vente, Kamphuis, Emmelkamp, \& Blonk, 2008). 
These recommendations contain a caveat: certain appraisals "are not in and of themselves appropriate or inappropriate, effective or ineffective" (Lazarus \& Folkman, 1984, p. 185). The value of an appraisal depends on the context. As such, we do not blindly recommend nullifying negative and encouraging challenge appraisals of incivility. Although negative (challenge) appraisals are often associated with detrimental (beneficial) outcomes, readers should consider the individuals, contexts, and outcomes involved before implementing interventions.

In conclusion, our project unpacks pathways to incivility harm as well as benefit. We demonstrate when and why employees can derive developmental gain from uncivil treatment on the job. This dark side of organizational life, it appears, does let in moments of light. 


\section{References}

Abramson, L. Y., Seligman, M. E., \& Teasdale, J. D. (1978). Learned helplessness in humans: Critique and reformulation. Journal of Abnormal Psychology, 87(1), 49-74.

Adler, J. M., Lodi-Smith, J., Philippe, F. L., \& Houle, I. (2016). The incremental validity of narrative identity in predicting well-being: A review of the field and recommendations for the future. Personality and Social Psychology Review, 20(2), 142-175.

Alea, N., \& Vick, S. C. (2010). The first sight of love: Relationship-defining memories and marital satisfaction across adulthood. Memory, 18(7), 730-742.

Andersson, L. M., \& Pearson, C. M. (1999). Tit for tat? The spiraling effect of incivility in the workplace. Academy of Management Review, 24, 452-471.

Beck, A. T. (1975). Cognitive therapy and the emotional disorders. New York, NY: International Universities Press.

Bergman, M. E., Langhout, R. D., Palmieri, P. A., Cortina, L. M., \& Fitzgerald, L. F. (2002). The (un)reasonableness of reporting: Antecedents and consequences of reporting sexual harassment. Journal of Applied Psychology, 87(2), 230-242.

Betancourt, H., \& Blair, I. (1992). A cognition (attribution)-emotion model of violence in conflict situations. Personality and Social Psychology Bulletin, 18(5), 343-350.

Bohner, G., Bless, H., Schwarz, N., \& Strack, F. (1988). What triggers causal attributions? The impact of valence and subjective probability. European Journal of Social Psychology, 18, $335-345$.

Braun, V., \& Clarke, V. (2006). Using thematic analysis in psychology. Qualitative Research in Psychology, 3, 77-101.

Brees, J. R., Mackey, J., \& Martinko, M. J. (2013). An attributional perspective of aggression in 
organizations. Journal of Managerial Psychology, 28(3), 252-272.

Cammann, C., Fichman, M., Jenkins, D., \& Klesh, J. R. (1983). The Michigan Organizational Assessment Questionnaire. In S. E. Seashore (Ed.), Assessing organizational change: A guide to methods, measures, and practices (pp. 71-138). New York, NY: Wiley.

Chan, D. (2009). So why ask me? Are self-report data really that bad? In C. E. Lance \& R. J. Vandenberg (Eds.), Statistical and methodological myths and urban legends: Doctrine, verity, and fable in the organizational and social sciences (pp. 309-336). New York, NY: Routledge.

Clark, M. S., \& Grote, N. K. (1998). Why aren’t indices of relationship costs always negatively related to indices of relationship quality? Personality and Social Psychology Review, 2, 2-

\section{7.}

Cortina, L. M., \& Magley, V. J. (2009). Patterns and profiles of response to incivility in the workplace. Journal of Occupational Health Psychology, 14, 272-288.

Cortina, L. M., Magley, V. J., Williams, J. H., \& Langhout, R. D. (2001). Incivility in the workplace: Incidence and impact. Journal of Occupational Health Psychology, 6(1), 64-80.

de Vente, W., Kamphuis, J. H., Emmelkamp, P. M. G., \& Blonk, R. W. B. (2008). Individual and group cognitive-behavioral treatment for work-related stress complaints and sickness absence: A randomized controlled trial. Journal of Occupational Health Psychology, 13(3), 214-231.

Dillman, D. A., Smyth, J. D., \& Christian, L. M. (2008). Internet, mail, and mixed-mode surveys: The Tailored Design Method. Hoboken, NJ: John Wiley \& Sons.

Doty, D. H., \& Glick, W. H. (1998). Common methods bias: Does common methods variance really bias results? Organizational Research Methods, 1, 374-406. 
Edmonson, A. C., \& McManus, S. E. (2007). Methodological fit in management field research. Academy of Management Review, 32(4), 1155-1179.

Eschleman, K. J., Bowling, N. A., Michel, J. S., \& Burns, G. N. (2014). Perceived intent of supervisor as a moderator of the relationships between abusive supervision and counterproductive work behaviours. Work \& Stress, 28(4), 362-375.

Fazio, R. H. (1990). Multiple processes by which attitudes guide behavior: The MODE model as an integrative framework. In M. P. Zanna (Ed.), Advances in experimental social psychology (Vol. 23, pp. 75-109). San Diego, CA: Academic Press.

Folkman, S., \& Moskowitz, J. T. (2000a). Positive affect and the other side. American Psychologist, 55(6), 647-654.

Folkman, S., \& Moskowitz, J. T. (2000b). Stress, positive emotion, and coping. Current Directions in Psychological Science, 9(4), 115-118.

Furnham. A., Sadka, V., \& Brewin, C. R. (1992). The development of an Occupational Attributional Style Questionnaire. Journal of Organizational Behavior, 13(1), 27-39.

Gosling, S. D., Vazire, S., Srivastava, S., \& John, O. P. (2004). Should we trust web-based studies? A comparative analysis of six preconceptions about internet questionnaires. American Psychologist, 59(2), 93-104.

Heider, F. (1958). The psychology of interpersonal relations. New York: Wiley.

Hershcovis, M. S. (2011). "Incivility, social undermining, bullying...oh my!”: A call to reconcile constructs within workplace aggression research. Journal of Organizational Behavior, 31, 499-519.

Hobfoll, S. E. (1989). Conservation of resources: A new attempt at conceptualizing stress. American Psychologist, 44(3), 513-524. 
Hollenbeck, J. R. (2008). The role of editing in knowledge development: Consensus shifting and consensus creation. In Y. Baruch, A. M. Konrad, H. Aguinis \& W. H. Starbuck (Eds.), Journal Editing: Opening the Black Box (pp.16-26). San Francisco: Jossey Bass.

Hu, L., \& Bentler, P. M. (1999). Cutoff criteria for fit indexes in covariance structure analysis: Conventional criteria versus new alternatives. Structural Equation Modeling, 6(1), 1-55. Huang, J. L., Liu, M., \& Bowling, N. A. (2015). Insufficient effort responding: Examining an insidious confound in survey data. Journal of Applied Psychology, 100(3), 828-845.

Ilies, R., Aw, S. S. Y., \& Pluut, H. (2015). Intraindividual models of employee well-being: What have we learned and where do we go from here? European Journal of Work and Organizational Psychology, 24(6), 827-838.

Jones, E. E., \& Davis, K. E. (1965). From acts to dispositions the attribution process in person perception. Advances in Experimental Social Psychology, 2, 219-266.

Jones, E. E., \& Harris, V. A. (1967). The attribution of attitudes. Journal of Experimental Social Psychology, 3(1), 1-24.

Judge, T. A., \& Hulin, C. L. (1993). Job satisfaction as a reflection of disposition: A multiple source causal analysis. Organizational Behavior \& Human Decision Processes, 56, 388421.

Judge, T. A., Thoresen, C. J., Bono, J. E., \& Patton, G. K. (2001). The job satisfaction-job performance relationship: A qualitative and quantitative review. Psychological Bulletin, $127(3), 376-407$.

Keashly, L., \& Neuman, J. H. (2008). Aggression at the service delivery interface: Do you see what I see? Journal of Management and Organization, 14, 180-192.

Kelley, H. H., \& Michela, J. L. (1980). Attribution theory and research. Annual Review of 


\section{Psychology, 31, 457-501.}

Kent, R. L., \& Martinko, M. J. (1995). The measurement of attributions in organizational research. In M. J. Martinko (Ed.), Attribution theory: An organizational perspective (pp. 1734). Delray Beach, FL: St. Lucie Press.

Langhout, R. D., Bergman, M. E., Cortina, L. M., Fitzgerald, L. F., Drasgow, F., \& Williams, J. H. (2005). Sexual harassment severity: Assessing situational and personal determinants and outcomes. Journal of Applied Social Psychology, 35(5), 975-1007.

Lazarus, R. S. (2000). Toward better research on stress and coping. American Psychologist, $55(6), 665-673$.

Lazarus, R. S., \& Folkman, S. (1984). Selections in stress, appraisal, and coping. New York: Springer Publishing.

Lee, K., \& Allen, N. J. (2002). Organizational citizenship behavior and workplace deviance: The role of affect and cognitions. Journal of Applied Psychology, 87(1), 131-142.

Lim, S., Cortina, L. M., \& Magley, V. J. (2008). Personal and workgroup incivility: Impact on work and health outcomes. Journal of Applied Psychology, 9(1), 95-107.

Lim, V. K. G., \& Teo, T. S. H. (2009). Mind your e-manners: Impact of cyber incivility on employees' work attitude and behavior. Information and Management, 46, 419-425.

Martinko, M. J., Harvey, P., \& Douglas, S. C. (2007). The role, function, and contribution of attribution theory to leadership: A review. The Leadership Quarterly, 18, 561-585.

Martinko, M. J., Gundlach, M. J., \& Douglas, S. C. (2002). Toward an integrative theory of counterproductive work behavior: A causal reasoning perspective. International Journal of Selection and Assessment, 10(1/2), 36-50.

Martinko, M. J., \& Zellars, K. L. (1998). Toward a theory of workplace violence and aggression: 
A cognitive appraisal perspective. In R. W. Griffin, A. O’Leary-Kelly, and J. M. Collins (Eds.), Dysfunctional behavior in organizations (Vol. 1, pp. 1-42). Stamford, CT: JAI Press. Matsunaga, M. (2011). Underlying circuits of social support for bullied victims: An appraisalbased perspective on supportive communication and postbullying adjustment. Human Communication Research, 37, 174-206.

Mazzeo, S. E., Bergman, M. E., Buchanan, N. T., Drasgow, F., \& Fitzgerald, L. F. (2001). Situation-specific assessment of sexual harassment. Journal of Vocational Behavior, 59, $120-131$.

Milam, A. C., Spitzmueller, C., \& Penney, L. M. (2009). Investigating individual differences among targets of workplace incivility. Journal of Occupational Health Psychology, 14(1),

\section{8-69.}

Miller, D. T. (2001). Disrespect and the experience of injustice. Annual Review of Psychology, $52,527-553$.

Miner-Rubino, K., \& Cortina, L. M. (2007). Beyond targets: Consequences of vicarious exposure to misogyny at work. Journal of Applied Psychology, 92(5), 1254-1269.

Moskowitz, J. T., Folkman, S., \& Acree, M. (2003). Do positive psychological states shed light on recovery from bereavement? Findings from a 3-year longitudinal study. Death Studies, $27,471-500$.

Ohly, S., \& Fritz, C. (2010). Work characteristics, challenge appraisal, creativity, and proactive behavior: A multi-level study. Journal of Organizational Behavior, 31, 543-565.

Organ, D. W., \& Ryan, K. (1995). A meta-analytic review of attitudinal and dispositional predictors of organizational citizenship behavior. Personnel Psychology, 48, 775-802.

Pearson, C. M., \& Porath. C. L. (2005). On the nature, consequences, and remedies of workplace 
incivility: No time for 'nice'? Think again. Academy of Management Executive, 19(1), 7-18.

Philippe, F. L., Koestner, R., Beaulieu-Pelletier, G., Lecours, S., Lekes, N. (2012). The role of episodic memories in current and future well-being. Personality and Social Psychology

\section{Bulletin, 38(4), 505-519.}

Philippe, F. L., Koestner, R., Lecours, S., Beaulieu-Pelletier, G. \& Bois, K. (2011). The role of autobiographical memory networks in the experience of negative emotions: How our remembered past elicits our current feelings. Emotion, 11(6), 1279-1290.

Pillemer, D. (2003). Directive functions of autobiographical memory: The guiding power of the specific episode. Memory, 11(2), 193-202.

Peterson, C., Semmel, A., von Baeyer, C., Abramson, L. Y., Metalsky, G. I., Seligman, M. E. P. (1982). The Attributional Style Questionnaire. Cognitive Therapy and Research, 6, 287-300.

Podsakoff, P. M., LePine, J. A., \& LePine, M. A. (2007). Differential challenge stressorhindrance stressor relationships with job attitudes, turnover intentions, turnover, and withdrawal behavior: A meta-analysis. Journal of Applied Psychology, 92(2), 438-454.

Podsakoff, P. M., MacKenzie, S. B., Paine, J. B., \& Bachrach, D. G. (2000). Organizational citizenship behaviors: A critical review of the theoretical and empirical literature and suggestions for future research. Journal of Management, 26(3), 513-563.

Podsakoff, P. M., MacKenzie, S. B., \& Podsakoff, N. P. (2012). Sources of method bias in social science research and recommendations on how to control it. Annual Review of Psychology, $65,539-569$

Porath, C. L., \& Erez, A. (2007). Does rudeness really matter? The effects of rudeness on task performance and helpfulness. Academy of Management Journal, 50(5), 1101-1197.

Porath, C. L., \& Pearson, C. M. (2012). Emotional and behavioral responses to workplace 
incivility and the impact of hierarchical status. Journal of Applied Social Psychology, 42 (S1), E326-E357.

Porath, C. L., Spreitzer, G., Gibson, C., \& Garnett, F. (2012). Thriving at work: Toward its measurement, construct validation, and theoretical refinement. Journal of Organizational Behavior, 33, 250-275.

Riketta, M. (2008). The causal relation between job attitudes and performance: A meta-analysis of panel studies. Journal of Applied Psychology, 93(2), 472-481.

Russell, D. (1982). The Causal Dimension Scale: A measure of how individuals perceive causes. Journal of Personality and Social Psychology, 42(6), 1137-1145.

Schaefer, J. A., \& Moos, R. H. (1992). Life crises and personal growth. In B. N. Carpenter (Ed.), Personal coping: Theory, research, and application (pp. 149-170). Westport, CT: Praeger.

Schaefer, J. A., \& Moos, R. H. (1998). The context for posttraumatic growth: Life crises, individual and social resources, and coping. In R. G. Tedeschi, C. L. Park, and L. G. Calhoun (Eds.), Posttraumatic growth: Positive changes in the aftermath of crisis (pp. 99126). Mahwah, NJ: Lawrence Erlbaum Associates.

Scheier, M. F., \& Carver, C. S., \& Bridges, M. W. (1994). Distinguishing optimism from neuroticism (and trait anxiety, self-mastery, and self-esteem): A re-evaluation of the Life Orientation Test. Journal of Personality and Social Psychology, 67, 1063-1078.

Schweiger, D., \& DeNisi, A. (1991). Communication with employees following a merger: A longitudinal field experiment. Academy of Management Journal, 34, 110-135.

Sinclair, R. R., Martin, J. E., \& Croll, L. E. (2002). A threat-appraisal perspective on employees' fears about antisocial workplace behavior. Journal of Occupational Health Psychology, 7, $37-56$. 
Spell, C. S., \& Arnold, T. (2007). An appraisal perspective of justice, structure, and job control as antecedents of psychological distress. Journal of Organizational Behavior, 28, 729751.

Spreitzer, G., Sutcliffe, K., Dutton, J., Sonenshein, S., \& Grant, A. M. (2005). A socially embedded model of thriving at work. Organization Science, 16(5), 537-549.

Stein, N., Folkman, S., Trabasso, T., \& Richards, T. A. (1997). Appraisal and goal processes as predictors of psychological well-being in bereaved caregivers. Journal of Personality and Social Psychology, 72(4), 872-884.

Struthers, C. W., Eaton, J., Mendoza, R., Santelli, A. G., \& Shirvani, N. (2010). Interrelationship among injured parties' attributions of responsibility, appraisal of appropriateness to forgive the transgressor, forgiveness, and repentance. Journal of Applied Social Psychology, 40(4), 970-1002.

Tomaka, J., Blascovich, J., Kelsey, R. M., \& Leitten, C. L. (1993). Subjective, physiological, and behavioral effects of threat and challenge appraisal. Journal of Personality and Social Psychology, 65(2), 248-260.

Vangelisti, A. L., \& Young, S. L. (2000). When words hurt: The effects of perceived intentionality on interpersonal relationships. Journal of Social and Personal Relationships, $17,393-424$.

Weiner, B., Amirkhan, J., Folkes, V. S., \& Verette, J. A. (1987). An attributional analysis of excuse giving: Studies of a naïve theory of emotion. Journal of Personality and Social Psychology, 52(2), 316-324. 
Table 1

Study 1 Descriptive Statistics, Scale Reliabilities, and Inter-variable Correlations

\begin{tabular}{|c|c|c|c|c|c|c|c|c|}
\hline Variable & $M$ & $S D$ & 1 & 2 & 3 & 4 & 5 & 6 \\
\hline 1. Job Satisfaction & 5.61 & 1.24 & .87 & & & & & \\
\hline 2. Perpetrator Control & 3.79 & 1.13 & .04 & .64 & & & & \\
\hline 3. Perpetrator Intent & 3.24 & 1.42 & $-.11 *$ & $.33 * * *$ & $n / a$ & & & \\
\hline 4. Negative Appraisal & 2.94 & 1.03 & $-.20 * * *$ & $.29 * * *$ & $.43 * * *$ & .92 & & \\
\hline 5. Incivility History & 1.79 & .67 & $-.33 * * *$ & $.29 * * *$ & $.32 * * *$ & $.51 * * *$ & .88 & \\
\hline 6. Pessimism & 2.18 & .67 & $-.26 * * *$ & -.01 & .07 & .09 & $.15^{* *}$ & .83 \\
\hline
\end{tabular}

Note. Scale reliabilities (Cronbach's alphas) are italicized along the diagonal.

$* p<.05 ; * * p<.01 ; * * * p<.001$. 
Table 2

Study 2 Descriptive Statistics, Scale Reliabilities, and Inter-variable Correlations

\begin{tabular}{|c|c|c|c|c|c|c|c|c|c|c|c|}
\hline Variable & $M$ & $S D$ & 1 & 2 & 3 & 4 & 5 & 6 & 7 & 8 & 9 \\
\hline 1. Job Satisfaction & 5.42 & 1.45 & .91 & & & & & & & & \\
\hline 2. Thriving - Learning & 5.46 & 1.19 & $.67 * * *$ & .91 & & & & & & & \\
\hline 3. Thriving - Vitality & 5.07 & 1.43 & $.76^{* * *}$ & $.79 * * *$ & .94 & & & & & & \\
\hline 4. Perpetrator Intent & 3.23 & .89 & $-.25 * * *$ & $-.11 *$ & $-.16^{* *}$ & .84 & & & & & \\
\hline 5. Negative Appraisal & 2.87 & .97 & $-.21 * * *$ & -.07 & $-.15 * *$ & $.38 * * *$ & .88 & & & & \\
\hline 6. Challenge Appraisal & 1.90 & .95 & $.21 * * *$ & $.26^{* * *}$ & $.27 * * *$ & -.06 & $.16^{* *}$ & .88 & & & \\
\hline 7. Incivility History & 1.64 & .75 & $-.39 * * *$ & $-.22 * * *$ & $-.29 * * *$ & $.34 * * *$ & $.41 * * *$ & $.23 * * *$ & .92 & & \\
\hline 8. Pessimism & 2.42 & .83 & $-.48 * * *$ & $-.47 * * *$ & $-.59 * * *$ & $.12 *$ & $.14^{*}$ & $-.17 * *$ & $.28 * * *$ & .89 & \\
\hline 9. OCB (coworker-rated) & 3.96 & .77 & $.28 * * *$ & $.34 * * *$ & $.35 * * *$ & .03 & -.01 & -.01 & $-.26 * *$ & $.24 * *$ & .95 \\
\hline
\end{tabular}

Note. Scale reliabilities (Cronbach's alphas) are italicized along the diagonal. OCB $=$ Organizational Citizenship Behavior. $* p<.05 ; * * p<.01 ; * * * p<.001$ 


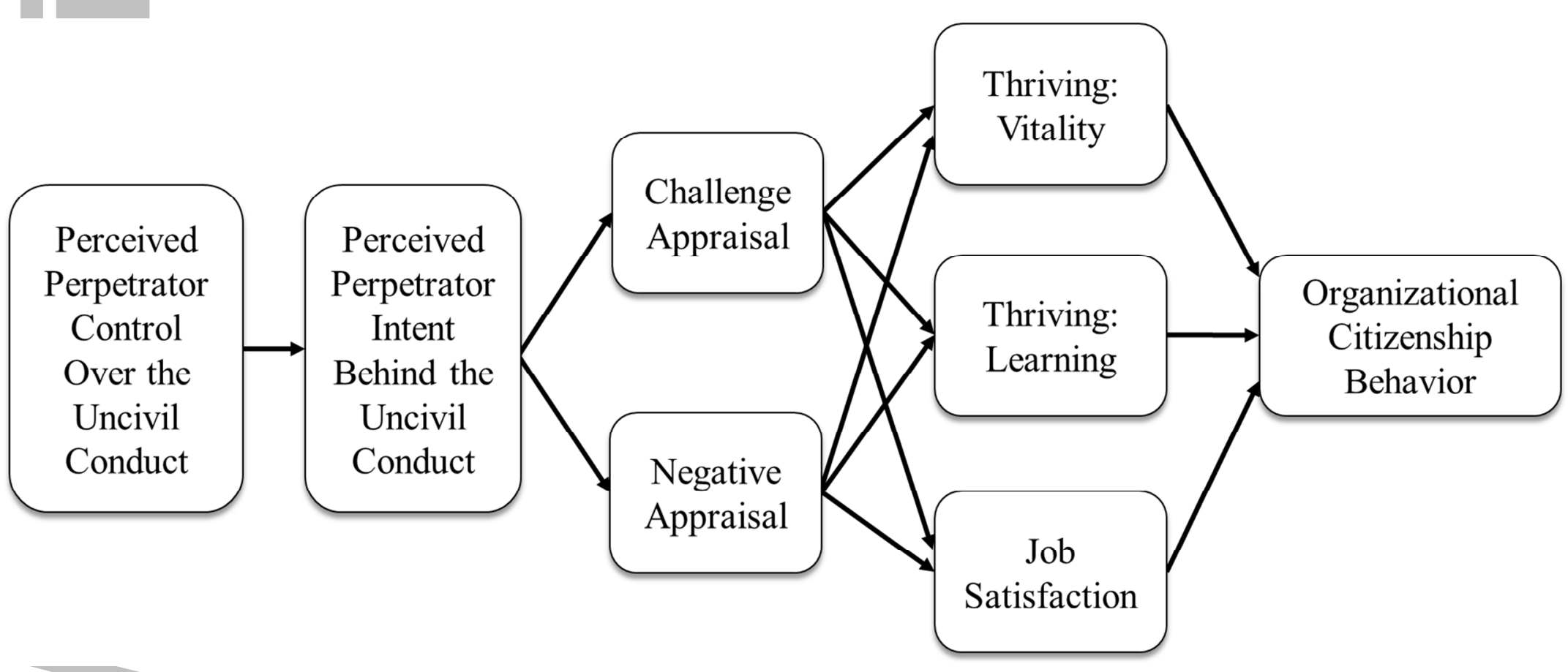

Figure 1. Heuristic diagram of all hypothesized relationships. 


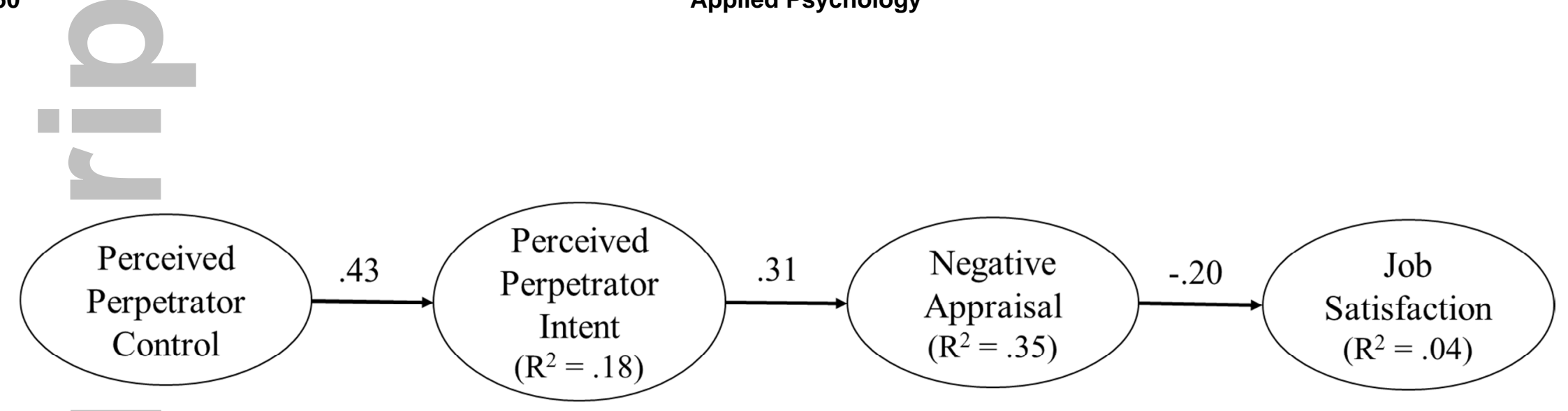

Figure 2. Study 1 structural model results $(n=331)$. Pessimism and incivility history are included as control variables. All paths shown are statistically significant. Not shown are correlations between exogenous latent variables (control and pessimism: $\Phi=-.01$, $n s$; control and incivility history: $\Phi=.42, p<.05$; pessimism and incivility history: $\Phi=.15, p<.05$ ), nor paths from pessimism to negative appraisal $(\beta=.02, n s)$ and from incivility history to negative appraisal $(\beta=.46, p<.05)$. 


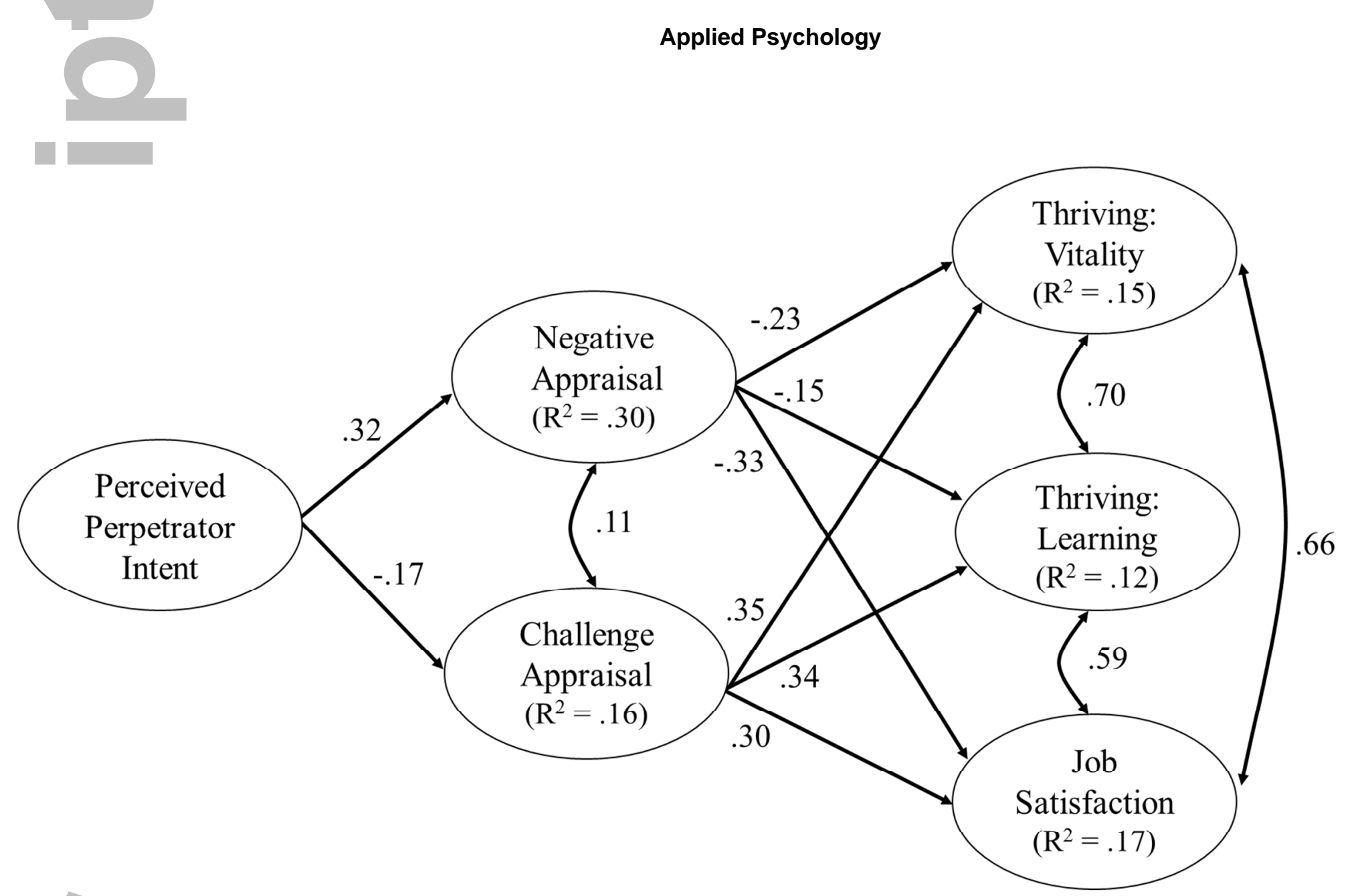

Figure 3. Study 2 structural model results $(n=350)$. Pessimism and incivility history are included as control variables. All paths shown are statistically significant. Not shown are correlations between exogenous latent variables (intent and pessimism: $\Phi=.14$; intent and incivility history: $\Phi=.37$; pessimism and incivility history: $\Phi=.26$; all statistically significant), nor paths from pessimism to negative and challenge appraisals ( $\beta=.05, n s$ and $\beta=-.29, p<.01$, respectively) and from incivility history to negative and challenge appraisals $(\beta=.33$ and $\beta=.37$, respectively, both $p<.01)$. 